Article

\title{
Rapid Development, Build-Out Ratio and Subsequent Neighborhood Turnover
}

\author{
George O. Rogers ${ }^{1}$ (D) and Yunmi Park ${ }^{2, *}$ (i) \\ 1 Department Landscape Architecture and Urban Planning, Texas A\&M University, \\ College Station, TX 77843, USA; grogers@tamu.edu \\ 2 Department Architectural and Urban System Engineering, Ewha Womans University, Seoul 03760, Korea \\ * Correspondence: ymp@ewha.ac.kr; Tel.: +82-2-3277-3468
}

Received: 23 March 2018; Accepted: 23 April 2018; Published: 25 April 2018

check for updates

\begin{abstract}
Neighborhood development is primarily comprised of structural elements that include design elements, nearby amenities and ecological attributes. This paper assumes that the process of development itself also influences the character of the neighborhood-specifically, that the rate of development and build-out ratio influences neighborhood turnover. While the structural components clearly set a framework for development, the process of development expresses the character of the neighborhood in subtle messages conveyed through the market. Neighborhoods in the rapidly growing university town of College Station, Texas are analyzed in terms of neighborhood design, nearby amenities and landscape ecology components. Residential property records are used to characterize each neighborhood in terms of the rate of development and current build-out ratio. The multivariate analysis indicates that the development rate increases subsequent neighborhood turnover rates while the build-out ratio decreases it.
\end{abstract}

Keywords: development rate; build-out ratio; neighborhood turnover; neighborhood satisfaction; neighborhood design

\section{Introduction}

Since 1960, the Census [1] has indicated that housing has started to consistently exceed a million a year. Housing prices fell from 190,200 per month in May of 2006 to a low of 31,900 in January of 2009, but have since recovered to a million-a-year level, beginning in 2012. From 1959 to 1999 housing starts averaged 125,800 per month with 69.1 percent being single unit structures. In this century, the rate has fallen to 105,400 per month with 76.3 percent being single unit structures. Hence, development is ongoing in communities as they adjust to local challenges, which means it is an important contributor to neighborhood satisfaction and community well-being. Jacobs [2] argued that neighborhoods are messy places that evolve into extremely complex systems. This suggests that the process of development may establish the character of a neighborhood in ways that have long-lasting impact on the residents. Consider the contrast between "instant" and "evolving" neighborhoods. In instant neighborhoods, residents become instant neighbors with limited or no experience or social structure on which to base these relationships. Also, those neighborhoods tend to fail to build community consensus with long-term horizon [3]. In evolving neighborhoods, new residents interact with existing residents, where they are integrated into existing social structures.

In this regard, this research attempts to examine the extent to which rapid developments of neighborhood impact subsequent neighborhood turnover. As is well-known, design, surrounding settings, and the process of development influence the fundamental character of the neighborhood, and hence are expected to influence neighborhood satisfaction. This paper examines them, by considering neighborhood turnover rates, as a broad indicator of neighborhood satisfaction, in terms 
of prior rate of development and build-out ratio, and neighborhood design elements, local amenities, landscape ecology characteristics, housing structure and market conditions. Turnover rates are used as a broad indicator of neighborhood satisfaction, reflecting a resident's willingness to stay, rather than "vote with their feet" by moving away. Also, it is assumed that neighborhood turnover is one of the critical factors in creating stable and more sustainable communities. The rate of development represents how quickly a neighborhood has been completed, while the build-out ratio represents the degree of completion at a given time. Lastly, the outcome of this paper is expected to help both planners and developers better understand how rapid development impacts neighborhood satisfaction and create better places.

\section{Background Literature}

\subsection{The Process of Development}

Urban development has been extensively discussed in the literature in terms of real estate development, neighborhood design, or evolutionary processes. Real estate development is often presented as a series of steps taken to develop a particular piece of property from initial purchase through design, financing and implementation to sale of property to end users [4,5]. Sirmans et al. [6] argue that because residential subdivisions are developed sequentially, early buyers face greater uncertainty; and developers often give discounts to early buyers to compensate for the additional risk they face consequently. They tested the relevant hypotheses in two small subdivisions of 52 and 54 households in Louisiana and Connecticut respectively; and confirm that properties developed later in the sequence increase in price, as the uncertainty associated with future development is resolved.

Neighborhood design is often examined in terms of the characteristics of the place and their impact on residents. It is generally believed that neighborhood design shapes the physical elements that induce growth, development and human activity $[7,8]$. Planners tend to be deterministic, which suggests that the physical environment largely shapes human growth, development and activities [9]. While the ultimate goals of planners and developers are divergent, they pursue well-designed neighborhoods. Planners recognize that well-designed neighborhoods tend to be healthy productive parts of the community; developers know that well-designed neighborhoods elicit a premium that can make the difference in the bottom line. There are a number of reasons a well-designed neighborhood may not achieve desired outcomes. For example, implemented designs may not follow design guides on details that taken as a whole can make a difference in the overall outcome; or resident preferences, and even their needs, may change over time, while the design remains relatively inflexible and unchanging, creating large gaps between what is and what is desired. Residents of traditionally designed neighborhoods prefer them, although they were slower to sell than other nearby areas [10]. Hidalgo and Hernandez [11] interviewed 177 people concerning physical and social place attachment. They found neighborhood attachment is least robust, and social attachment is greater than physical attachment. Sorensen, et al. [12] conducted a detailed case study of a neighborhood of 133 single-family houses in Charlotte, North Carolina. They showed a series of problems (e.g., isolation from amenity, noxious facilities nearby, and limited oversight) with the process of development from 2001 to 2014 resulted in more than 600 ownership transactions. Only 22 percent of the properties avoided foreclosure, and 16 of the 104 foreclosures resulted in at least a 25 percent loss. Charlotte is "...now faced with an increasingly difficult array of challenges as the neighborhood attempts to climb out of the abyss of foreclosure and general neighborhood decline" [12]. These problems are partly the result of the "tyranny of easy development decisions" [13-15].

Jacobs [2] argued that grand plans to redevelop large parts of a city according to some underlying theoretical framework are doomed to failure, because of the complex evolutionary nature of neighborhood development and its impact on the social relations in neighborhoods. She favored a gradual redevelopment that allows existing social relationships to continue while new relationships are established. King [16] quantitatively examined the hypothesis that gradual redevelopment resulting 
in a historical diversity of housing type strengthens social relations in a neighborhood. King [16] linked a survey sample of 3105 adults in 343 Chicago neighborhoods. Her results show that historical diversity significantly improves social relations, which supports Jacob's claims. Note that the research reported above, is conducted at the individual household level, which implicitly suggests that the concern is individual household satisfaction and turnover. This paper explicitly examines the extent to which the rate of development and build-out in a neighborhood are related to subsequent turnover therein.

\subsection{Neighborhood Turnover}

Neighborhood turnover is the rate of change in occupation, but is most often operationalized in terms of the change of ownership and expressed as the number of changes per unit time. Neighborhood turnover is most often used to predict a series of social ills ranging from reduced property values, to declining schools, to racial segregation. As turnover increases, the social fabric of the neighborhood is more likely to fluctuate, with rapid declines in attachment to place, social integration, or informal social control. Hence, turnover is often regarded as a precondition for an array of social pathologies in neighborhoods [17-19]. Neighborhood stability is typically seen as good for communities [18]; however, in socially isolated and disadvantaged neighborhoods stability can mean residents are unable to move-being trapped by circumstances. Neighborhood stability has been linked to both a strong cohesiveness and social isolation among neighbors. Ross, Reynolds and Geis [18] found that among affluent neighborhoods the stability of low residential turnover reduces distress, while poor neighborhoods tend to experience the opposite.

Segregation is often discussed in conjunction with turnover-in particular white flight. Some communities have experienced rapid change in racial composition. Even the early "pioneers" that started the rapid change by moving into in some communities, found themselves moving out as the community itself changed into a less desirable place. A neighborhood characterized by high residential turnover is changing rapidly, which creates uncertainty for existing residents. These neighborhoods experience a place where relatively few people know one another, where residential turnover is high/stability is low, and community cohesiveness is at a minimum [20].

Schelling [21,22] mathematically demonstrated that even when residents are willing to live in mixed neighborhoods, almost complete segregation results. In any group with dichotomous types, only one of the types can be numerically superior. Hence, Schelling [22] notes that while the ratio between types for the whole group is given, the local majority can be of either type. If each type insists on being the local majority, only complete segregation can be satisfactory. Only when there is an exact 50-50 mixture, will the mixture be self-sustaining. When all actors of each type are happy and completely satisfied with their circumstances, there is no movement. Schelling [22] suggested that blacks and whites "...may even prefer integration, but may nevertheless wish to avoid minority status." If both types can tolerate minority status, as long as it is not too extreme then mixes, within tolerance will survive, but beyond the extreme "...mixtures will lose their minority members and become..." homogeneous but segregated. Several conclusions are worthy of note here. (1) Small preferences among individuals can aggregate to strong patterns - it does not take racism to produce segregation. (2) Initial conditions matter-natural interaction will tend to perpetuate initial conditions.

While most of the evidence is anecdotal, quantitative research suggests more subtle impacts. For example, in a quantitative analysis of 39 large metropolitan areas, Frey [23] suggested that racial and nonracial factors that affect the flight from central city are more about the choice of destination than the decision to leave. Goering [24] examined the empirical evidence of a "tipping point" in neighborhoods. The evidence suggests that there may be specific cases of neighborhoods suddenly experiencing rapid change under specific conditions; however, evidence also exists for neighborhoods experiencing changes in a relatively continuous process. [25] found that turnover among whites increases significantly as the proportion of minority residents increases and these results persist in multivariate models that account for a wide range of predictors. These effects are less robust than 
might be expected; they are modest, non-linear, vary with individual characteristics, and depend on housing availability.

\section{Research Method}

\subsection{Hypotheses}

Based on the literature and research questions, this article attempts to explore the role of the development rate and build-out ratio of a neighborhood in establishing the character of a place under two following hypotheses. Hypothesis 1 examines the relationship between the rate of development in the prior period and neighborhood satisfaction as reflected in the current neighborhood turnover rate; while Hypothesis 2 examines the relationship between build-out ratio at the beginning of the period and current turnover rate.

- Hypothesis 1: The greater the rate of development, the greater neighborhood turnover in the subsequent period. As Schelling [21,22] pointed out, if residents are completely happy (satisfied) turnover will not exist. While there are a number of reasons for moving, enhanced neighborhood satisfaction will be reflected in reduced turnover. The first hypothesis examines the relationship between the development rate and neighborhood turnover. It is argued that the development rate establishes a character that persists in the neighborhood. Hypothesis 1 suggests that the faster the rate of development the more transient the neighborhood becomes, which reduces satisfaction and increases neighborhood turnover in subsequent periods.

- Hypothesis 2: The greater neighborhood built-out ratio, the lower the neighborhood turnover in the subsequent period. The second hypothesis examines the relationship between build-out and neighborhood turnover. That is the impact of where the neighborhood is in terms of being completed and residential turnover. This recognizes the concerns Sirmans, Turnbull and Dombrow [6] that early buyers have less information about the neighborhood when they make their purchase decisions. Late buyers have a nearly complete picture of what the neighborhood will be like as it nears completion. Moreover, as a neighborhood develops there is a diminishing availability. Ending with the neighborhood being completely built-out. Hypothesis 2 suggests that as a neighborhood is built-out, the nature of the neighborhood is less uncertain. The uncertainty of the unknown future of a partially built neighborhood is replaced by the reality of the completed neighborhood, which reduces the residential turnover rate.

These two hypotheses will be examined in the context of neighborhood design, street pattern, nearby amenities, landscape ecology of the neighborhood, and market which potentially influence residential turnover in a neighborhood.

\subsection{Study Area and Data Collection}

College Station, Texas is a rapidly growing university town; increasing from 2184 people in 1940 to 100,050 in 2014. College Station is the 82 nd fastest growing city in 2014 among the 714 cities of 50,000 or more with a growth rate of 6.4 percent [26]. The surrounding area is also growing rapidly-Brazos County is the 39th fastest growing county in 2013 [26].

Revealed preference data reflect economic behavior in terms of consumer choice $[27,28]$. The property records used herein reflect consumer decisions aggregated to the neighborhood level. Property records show that 17,194 single-family parcels in 251 uniquely named subdivisions were developed prior to 2014 under the city's jurisdiction. Subdivisions developed in phases under the same name are considered one unique neighborhood. Boundaries were carefully modified creating independent neighborhoods when (1) subdivisions with the same name are separated by significant barriers (e.g., major arterial roads, highways, greenways) or are simply geographically discontinuous areas; (2) subdivisions nested within a larger subdivision are considered one neighborhood; and (3) geographically close subdivisions that share the same entrance are considered 
one neighborhood. Neighborhoods with less than five parcels were excluded, as they are not large enough to form a "residential neighborhood" and observe a "meaningful" development rate. Appraisal data for 15,456 single-family parcels in 157 neighborhoods were selected for the analysis (see Figure 1).

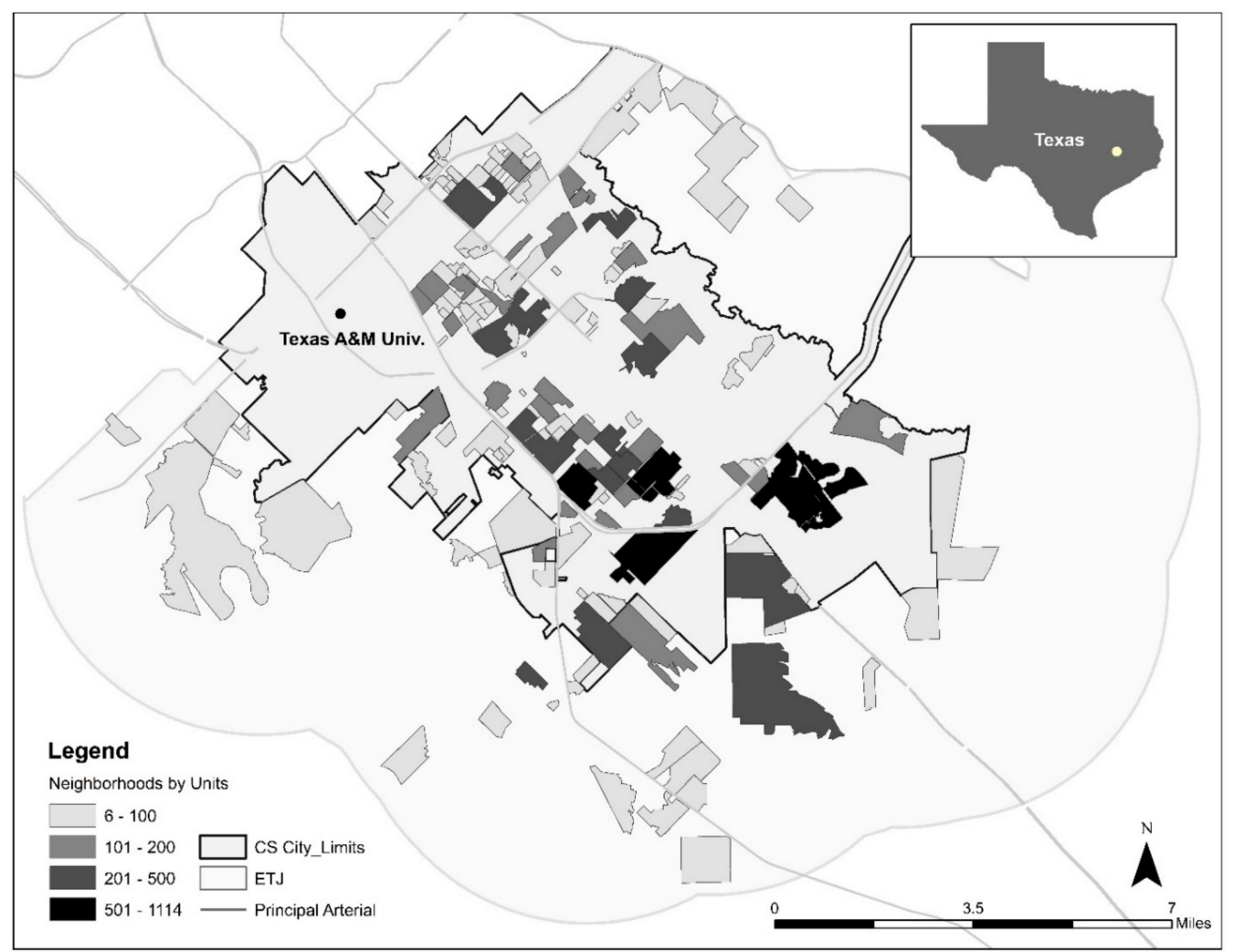

Figure 1. Study Area and Its Neighborhoods: College Station, Texas.

The appraisal data provide geographic location, built year, lot size, and appraised value of each parcel. The deed-change data record the history of transactions of buyers and sellers of each property. Deed-changes before construction are not considered owner changes since these activities reflect change of landowners only, not residents. Both appraisal data and deed data were purchased from Brazos County Appraisal District in September 2013.

The geographic boundaries of subdivisions, streets and roads, lakes, streams and rivers, and locations of elementary schools were obtained from the College Station Geographic Information Services in August 2013. These data represent the City of College Station and areas under its extraterritorial jurisdiction (ETJ) — adjacent geographic areas within five miles of corporate boundary. Section 42.021 of the September 1987 Determination of Extraterritorial Jurisdiction Act has five distance categories-municipalities with more than 100,000 inhabitants are have 5-mile ETJ buffers. The grocery store data were obtained from the Food and Nutrition Service in U.S. Department of Agriculture in December 2013 and then geocoded by ArcGIS 10.1. Land cover data was created based on 1-meter color infrared high-resolution digital ortho quadrangles imageries (DOQs) as of 2010 from the Texas Natural Resources Information System.

\subsection{Measurement}

The dependent variable, neighborhood turnover is a measure of the amount of real estate activity in a neighborhood. While the number of property sales in a neighborhood is a raw measure of real estate activity, it is adjusted for the number of years each property was available to be sold as a residence to better reflect neighborhood turnover. Hence, neighborhood turnover in a given period, 
$\mathrm{T}_{\mathrm{t}}$, is calculated as the total number of property sales in that period divided by the sum of years of all parcels that have been built-parcel-years,

$$
\mathrm{T}_{\mathrm{t}}=\mathrm{p}_{\mathrm{t}} / \mathrm{y}_{\mathrm{t}}
$$

where $p_{t}$ is sales transactions, which are summed over all available properties, $y_{t}$, is parcel-years, which are summed for the neighborhood. $T_{t}$ is logically equivalent to the average number of sales transactions in the neighborhood during the period divided by the number of years available: parcel-years. It is a likelihood measure of turnover on existing housing units during the period.

The development rate is a measure of the speed of development in a neighborhood. The rate of development, $D_{t}$ amounts to the average change in built parcels during the period,

$$
D_{t}=d_{t} / Y
$$

where $d_{t}$ is the number of developed properties during the period, and $Y$ is the number of years in the period under consideration.

The total build-out ratio represents the degree of completion of the neighborhood at the end of the prior period. The build-out ratio, $B_{t}$, is total parcels built at the end of the period divided by total parcels platted in subdivision,

$$
\mathrm{B}_{\mathrm{t}}=\mathrm{b}_{\mathrm{t}} / \mathrm{P},
$$

where $b_{t}$ is the cumulative built properties at the end of the period and $\mathrm{P}$ is the total platted properties in the neighborhood.

Other conditions that could possibly affect the turnover were also considered in the analysis, including neighborhood design, landscape ecology, distance to amenities, development and housing conditions, and market. Neighborhood design is represented by total acreage, average lot size, and mixed use in terms of zoning for single-family, multi-family housing or commercial use. Street pattern considered length and density of streets and bike lanes, the length and area of sidewalks, the number, and density of 3-way and 4-way intersections, and the number and density of dead-end streets. Nearby amenities include both commercial outlets such as major grocery stores and specialty corner stores and public facilities such as elementary schools and parks, as well as natural amenities including lakes, streams and rivers in or near the neighborhood. In addition, being in the ETJ represents a bundle of city service and natural amenities. Landscape ecology includes consideration of trees, grass, and combined green areas. Each of the three landscape-types was considered in terms of overall area, percent coverage, length of edge, patch density, number of patches, landscape shape index, mean shape index and patch cohesion index. The detailed formula of each index is presented in Appendix A. The characteristics of development and housing structure are represented by the percent of developed area in the neighborhood, the number of built parcels, the average of year built and the last year built. Market was considered in terms average appraised value of the property in the neighborhood and Simpson's diversity index. Simpson's diversity index, $\lambda,[29]$ is equal to the probability that any two elements selected at random from a population will be of the same type. It is calculated as the weighted arithmetic mean of the proportional abundances using the proportional abundances themselves as the weights, or

$$
\lambda=\sum \mathrm{p}^{2},
$$

where $\mathrm{p}$ is the proportional abundance in each type. Simpson's diversity index considered diversity in the real estate market by decade (i.e., 2010+, 2000s, 1990s, 1980s, and 1970-), with all building prior to 1970 being considered as one type.

\subsection{Analytic Process}

The analysis began with the inspection of the descriptive statistics for each variable. This inspection showed that a natural log transformation of neighborhood turnover conformed 
better to normality assumptions required for regression analysis. Variables of interest were regressed on the natural log of neighborhood turnover. Variables exhibiting marginal significance $(\alpha<0.1)$ were selected as potentially contributing variables (Table 1). Zero-order Pearson correlations were used to identify potential problems with collinear pairs of variables (i.e., $|\gamma|>0.5$ ) were flagged and examined). For example, the number of built parcels was dropped from consideration because it is highly correlated with number of parcels and total developed area; parcels and developed area have ecology variables while fully representing the landscape features.

Table 1. Summary statistics for variables of potential.

\begin{tabular}{|c|c|c|c|c|c|}
\hline Variables & $\mathbf{N}$ & Mean & Std. Dev. & Min & Max \\
\hline Transactions / year (2010+) & 157 & 0.107 & 0.121 & 0.000 & 0.833 \\
\hline Transactions/year (2000s) & 149 & 0.177 & 0.171 & 0.013 & 0.800 \\
\hline Transactions/year (1990s) & 109 & 0.150 & 0.147 & 0.000 & 0.814 \\
\hline \multicolumn{6}{|l|}{ Development Process: } \\
\hline Developed/year (2000s) & 149 & 11.1 & 16.0 & 0.3 & 106.3 \\
\hline Developed/year (1990s) & 109 & 7.8 & 10.6 & 0.1 & 69.2 \\
\hline Developed/year (1980s) & 90 & 5.4 & 6.9 & 0.1 & 38.0 \\
\hline Build-out ratio (2009) & 152 & 0.824 & 0.213 & 0.010 & 1.000 \\
\hline Build-out ratio (1999) & 112 & 0.730 & 0.281 & 0.007 & 1.000 \\
\hline Build-out ratio (1989) & 90 & 0.615 & 0.325 & 0.007 & 1.000 \\
\hline \multicolumn{6}{|l|}{ Neighborhood Design: } \\
\hline Area (acre) & 157 & 107.3 & 180.4 & 3.9 & 1485.5 \\
\hline Lot size (sq. ft) & 157 & 55,412 & 85,480 & 3600 & 487,832 \\
\hline Dead-ends & 157 & 7.7 & 12.1 & 0.0 & 79.0 \\
\hline Dead-end Density & 157 & 0.110 & 0.093 & 0.000 & 0.515 \\
\hline \multicolumn{6}{|l|}{ Distance to Amenities: } \\
\hline Elementary School (ft) & 157 & 6676 & 5884 & 495 & 31,305 \\
\hline Major Grocery Store $(\mathrm{ft})$ & 157 & 9583 & 7824 & 1179 & 33,271 \\
\hline Specialty Grocery Shop (ft) & 157 & 9203 & 6714 & 794 & 31,742 \\
\hline Stream with Water $(\mathrm{ft})$ & 157 & 5143 & 3197 & 133 & 12,289 \\
\hline Park $_{(\mathrm{ft})}$ & 157 & 4104 & 5657 & 0 & 25,744 \\
\hline Neighborhood in ETJ & 157 & 0.223 & 0.418 & 0.000 & 1.000 \\
\hline \multicolumn{6}{|l|}{ Landscape Ecology: } \\
\hline Tree Ratio & 157 & 29.7 & 16.2 & 0.8 & 73.2 \\
\hline Mean Shape Index & 157 & 1.372 & 0.085 & 1.179 & 1.591 \\
\hline Grass Ratio & 157 & 29.9 & 8.1 & 11.4 & 56.3 \\
\hline Patch Index & 157 & 97.123 & 2.160 & 88.388 & 99.831 \\
\hline \multicolumn{6}{|l|}{ Developed: } \\
\hline Developed Area Ratio & 157 & 35.6 & 15.8 & 3.9 & 79.4 \\
\hline Number of Parcels & 157 & 107.5 & 153.1 & 10.0 & 1143.0 \\
\hline Year Built (ave) & 157 & 1990.3 & 16.3 & 1951.0 & 2012.3 \\
\hline Year Built (last) & 157 & 2004.2 & 11.3 & 1955.0 & 2013.0 \\
\hline \multicolumn{6}{|l|}{ Market: } \\
\hline Appraised Value & 157 & $\$ 215,718$ & $\$ 108,989$ & $\$ 40,704$ & $\$ 621,865$ \\
\hline Simpson Diversity Index & 157 & 0.564 & 0.298 & 0.000 & 1.000 \\
\hline
\end{tabular}

To test the time-lagged hypotheses, the neighborhood turnover (dependent) and development rate and build-out (independent) variables were measured in each period: 2010 to 2013, 2000 to 2009, 1990 to 1999, and 1980 to 1989. This allows the testing of the impact of development rate and build-out variables in the prior period on current neighborhood turnover. The regression model retained variables in a stepwise process based on contribution $(\alpha<0.05)$ to the model and low variance inflation factor (VIF < 5.0). Variables with functional similarity (e.g., distance to major and specialty grocery stores) were selected for their contribution, when eliminating the weaker variable also controlled variance 
inflation factor. Variables deemed of theoretical importance (e.g., parks, assessed value) that failed to contribute to the reduced model were subsequently forced into the reduced model, but none were retained. The simplified models for each period were checked for spatial autocorrelation using Stata module SPATDIAG. Neither a spatial-error, nor a spatial-lag model were needed to correct for spatial autocorrelation in any period. Finally, to garner additional causal insight, prior period neighborhood turnover was used to predict rate of development and build-out ratio in the current period.

\section{Findings}

The descriptive statistics presented in Table 1 show that the earlier time periods have fewer neighborhoods, which is reflected in the absence of data for subdivisions not yet developed in early periods.

The full regression model presented in Table 2 explains around 60 percent of the variance in the number of transactions per year in the neighborhoods (i.e., $R^{2}=0.594,0.636$, and 0.618 in the 2010s, 2000s, and 1990s respectively). The full model presented in Table 2 is clearly over-specified with VIF of four components exceeding ten, and sixteen variables not contributing $(\alpha>0.1)$ to the overall model. Several points are worth noting: (1) among neighborhood design elements, street patterns rather than total acreage or lot size are significant; (2) distance to grocery stores and specialty shops are not significant; (3) landscape ecology measures are mixed, depending on whether they represent grass or trees, and more sophisticated landscape ecology measures or the simple ratio of tree and grass coverage; and (4) neither Simpson's diversity index nor appraised value were significantly related to transactions. These relationships are consistent with expectations-providing construct validity.

The simplified models, presented in Table 3, continues to explain more than 55 percent of the variance in transactions per available-year in the first two periods and more than 50 percent in the earliest period $\left(R^{2}=0.561,0.552\right.$, and 0.520 in the 2010s, 2000s, and 1990s respectively), while controlling the variance inflation (VIF < 3.5) for all elements of the model. For the most part the reduced model shows that the direction and magnitude of impacts associated with each variable are stable. The simplified model of transactions per year shows that the development rate significantly $(\alpha<0.05)$ increases the neighborhood turnover in subsequent periods $(0.013,0.013$ and 0.016 in 2010+, 2000s, and 1990s respectively) confirming Hypothesis 1 . Hence increasing the development rate by one house per year, on average, would be expected to raise turnover in subsequent periods by 1.3, 1.3, and 1.6 percent, respectively. The simplified models in Table 3 also show that build-out ratio significantly $(\alpha<0.05)$ reduces turnover in the subsequent period in the 2010+ and 2000s period and marginally $(\alpha<0.1)$ reduced turnover in the 1990s $(-1.931,-1.081$ and -0.427 respectively), which confirms Hypothesis 2. This indicates that a one-tenth unit increase in build-out ratio contributes to decreasing turnover by $19.3 \%, 10.8 \%$, and $4.3 \%$ in these time periods respectively. The average year built in a neighborhood significantly $(\alpha<0.05)$ contributes to increased turnover $(0.013,0.009$, and 0.026 , in 2010+, 2000s, and 1990s, respectively). This means that neighborhoods built one year later on average, are 1.3, 0.9 and 2.6 percent more likely to turnover, respectively.

While the total number of dead-end streets tends to reduce neighborhood turnover $(-0.013$ and -0.011 in 2010+, and 2000s respectively), the density of dead-end streets seems to increase turnover (1.377 and 1.269 respectively). Because these seem to be at cross-purposes, a statistical experiment was conducted that re-examined the simplified model for large ( $>49$ parcels) and small ( $<50$ parcels) neighborhoods. This statistical experiment suggests that dead-end streets generally play a positive role in reducing residential turnover; however, when the density of dead-end streets becomes large (especially in small neighborhoods), the multiple sub-neighborhoods that arise contribute to turnover as cohesion in the overall neighborhood declines. Hence, dead-end streets can enhance the stability of a neighborhood, particularly among larger neighborhoods, where they create strong ties to the face-block neighborhood that the relatively short cul-de-sacs create. But too many dead-end streets in smaller neighborhoods can fracture the existing ties to the overall neighborhood and increase turnover. 
Table 2. Full regression models for the natural log of residential transactions per year by period (inclusive).

\begin{tabular}{|c|c|c|c|c|c|c|c|c|c|c|c|c|c|c|c|}
\hline & \multicolumn{5}{|c|}{2010 to 2013} & \multicolumn{5}{|c|}{2000 to 2009} & \multicolumn{5}{|c|}{1990 to 1999} \\
\hline & $\mathbf{b}$ & Std Err & $\mathbf{t}$ & prob & VIF & $\mathbf{b}$ & Std Err & $t$ & prob & VIF & $\mathbf{b}$ & Std Err & $t$ & prob & VIF \\
\hline \multicolumn{16}{|l|}{ Development Process: } \\
\hline Developed/year (2000s) & 0.010 & 0.009 & 1.15 & 0.252 & 14.370 & & & & & & & & & & \\
\hline Developed/year (1990s) & & & & & & 0.005 & 0.012 & 0.46 & 0.644 & 12.600 & & & & & \\
\hline Developed/year (1980s) & & & & & & & & & & & -0.002 & 0.011 & -0.21 & 0.836 & 3.010 \\
\hline Build-out ratio (2009) & -1.714 & 0.242 & -7.10 & 0.000 & 1.760 & & & & & & & & & & \\
\hline Build-out ratio (1999) & & & & & & -0.934 & 0.196 & -4.76 & 0.000 & 2.460 & & & & & \\
\hline Build-out ratio (1989) & & & & & & & & & & & -0.179 & 0.307 & -0.58 & 0.562 & 5.160 \\
\hline \multicolumn{16}{|l|}{ Neighborhood Design: } \\
\hline Area $(\text { acre) })^{*}$ & -0.130 & 0.416 & -0.31 & 0.755 & 3.830 & 0.617 & 0.352 & 1.75 & 0.083 & 3.720 & 0.038 & 0.405 & 0.09 & 0.925 & 3.280 \\
\hline Lot size $(\text { sq. } \mathrm{ft})^{* *}$ & -0.002 & 0.011 & -0.16 & 0.871 & 5.810 & -0.020 & 0.011 & -1.90 & 0.061 & 8.030 & -0.005 & 0.012 & -0.38 & 0.704 & 8.000 \\
\hline Dead-ends & -0.008 & 0.007 & -1.11 & 0.271 & 5.550 & -0.022 & 0.010 & -2.29 & 0.024 & 8.750 & -0.002 & 0.012 & -0.16 & 0.876 & 5.810 \\
\hline Dead-end Density & 1.345 & 0.618 & 2.18 & 0.031 & 2.070 & 0.921 & 0.575 & 1.60 & 0.113 & 1.800 & -0.454 & 0.679 & -0.67 & 0.506 & 1.860 \\
\hline \multicolumn{16}{|l|}{ Distance to Amenities: } \\
\hline Elementary School $_{(\mathrm{ft})^{*}}$ & -0.037 & 0.014 & -2.69 & 0.008 & 4.320 & 0.014 & 0.013 & 1.04 & 0.300 & 5.410 & 0.019 & 0.017 & 1.16 & 0.249 & 6.280 \\
\hline Major Grocery Store $(\mathrm{ft})^{*}$ & 0.013 & 0.012 & 1.14 & 0.257 & 3.920 & -0.004 & 0.011 & -0.36 & 0.719 & 4.780 & -0.001 & 0.015 & -0.09 & 0.927 & 6.090 \\
\hline Specialty Grocery Shop (ft) & -0.005 & 0.010 & -0.56 & 0.578 & 3.920 & 0.015 & 0.010 & 1.42 & 0.160 & 4.230 & 0.021 & 0.013 & 1.53 & 0.130 & 5.520 \\
\hline Stream with Water $\left(\mathrm{fft}^{* * *}\right.$ & 0.252 & 0.163 & 1.55 & 0.124 & 1.790 & -0.043 & 0.140 & -0.31 & 0.759 & 1.760 & -0.101 & 0.166 & -0.61 & 0.544 & 1.630 \\
\hline $\operatorname{Park}_{(\mathrm{ft})^{*}}$ & 0.021 & 0.015 & 1.40 & 0.164 & 4.780 & -0.032 & 0.015 & -2.09 & 0.040 & 4.800 & -0.010 & 0.017 & -0.59 & 0.561 & 4.620 \\
\hline Neighborhood in ETJ & -0.134 & 0.194 & -0.69 & 0.491 & 4.280 & -0.150 & 0.187 & -0.80 & 0.425 & 4.640 & -0.210 & 0.238 & -0.88 & 0.382 & 5.300 \\
\hline \multicolumn{16}{|l|}{ Landscape Ecology: } \\
\hline Tree Ratio & -0.010 & 0.009 & -1.09 & 0.279 & 14.740 & 0.012 & 0.009 & 1.36 & 0.176 & 11.060 & 0.002 & 0.010 & 0.18 & 0.861 & 9.170 \\
\hline Mean Shape Index & -1.130 & 0.750 & -1.51 & 0.135 & 2.720 & 0.243 & 0.675 & 0.36 & 0.719 & 2.340 & 1.171 & 0.839 & 1.40 & 0.168 & 2.240 \\
\hline Grass Ratio & -0.011 & 0.013 & -0.88 & 0.382 & 6.860 & -0.001 & 0.011 & -0.13 & 0.898 & 7.020 & -0.001 & 0.013 & -0.04 & 0.968 & 6.130 \\
\hline Patch Index & -0.065 & 0.038 & -1.71 & 0.089 & 4.370 & 0.092 & 0.032 & 2.83 & 0.006 & 4.410 & 0.023 & 0.038 & 0.60 & 0.547 & 4.420 \\
\hline \multicolumn{16}{|l|}{ Developed: } \\
\hline Developed Area Ratio & -0.008 & 0.010 & -0.75 & 0.456 & 16.780 & 0.017 & 0.009 & 1.83 & 0.070 & 15.040 & 0.014 & 0.011 & 1.25 & 0.216 & 15.050 \\
\hline Number of Parcels & -0.134 & 0.001 & -0.26 & 0.798 & 16.110 & -0.149 & 0.001 & 0.59 & 0.554 & 20.430 & 0.001 & 0.001 & 1.16 & 0.248 & 6.050 \\
\hline Year Built (ave) & 0.009 & 0.005 & 1.83 & 0.070 & 3.780 & 0.010 & 0.004 & 2.30 & 0.024 & 3.000 & 0.025 & 0.006 & 4.22 & 0.000 & 3.290 \\
\hline Year Built (last) & 0.008 & 0.005 & 1.75 & 0.083 & 1.970 & -0.005 & 0.004 & -1.18 & 0.243 & 2.050 & -0.005 & 0.005 & -0.99 & 0.327 & 2.170 \\
\hline \multicolumn{16}{|l|}{ Market: } \\
\hline Appraised Value $^{* * *}$ & 0.002 & 0.041 & 0.06 & 0.952 & 1.300 & 0.003 & 0.038 & 0.09 & 0.926 & 1.450 & -0.060 & 0.043 & -1.40 & 0.165 & 1.450 \\
\hline Simpson Diversity Index & 0.060 & 0.143 & 0.42 & 0.675 & 1.190 & -0.073 & 0.132 & -0.55 & 0.583 & 1.230 & 0.117 & 0.172 & 0.68 & 0.499 & 1.380 \\
\hline Constant $=$ & -26.468 & 8.021 & -2.51 & 0.013 & & -21.663 & 7.923 & -2.15 & 0.034 & & -46.593 & 11.698 & -3.14 & 0.003 & \\
\hline Adj R-squared $=$ & & 0.524 & & & & & 0.546 & & & & & 0.486 & & & \\
\hline $\mathrm{N}=$ & & 149 & & & & & 112 & & & & & 87 & & & \\
\hline
\end{tabular}

* Coefficients and standard errors are multiplied by $1000 ;{ }^{* *}$ by 10,$000 ; * * *$ by 100,000 
Table 3. Simplified regression models for the natural log of residential transactions per year by period (inclusive).

\begin{tabular}{|c|c|c|c|c|c|c|c|c|c|c|c|c|c|c|c|}
\hline & \multicolumn{5}{|c|}{2010 to 2013} & \multicolumn{5}{|c|}{2000 to 2009} & \multicolumn{5}{|c|}{1990 to 1999} \\
\hline & b & Std Err & $\mathrm{t}$ & prob & VIF & b & Std Err & $t$ & prob & VIF & b & Std Err & $t$ & prob & VIF \\
\hline \multicolumn{16}{|l|}{ Development Process: } \\
\hline Developed/year (2000s) & 0.013 & 0.004 & 3.23 & 0.002 & 2.940 & & & & & & & & & & \\
\hline Developed/year (1990s) & & & & & & 0.013 & 0.006 & 2.20 & 0.030 & 3.190 & & & & & \\
\hline Developed/year (1980s) & & & & & & & & & & & 0.016 & 0.007 & 2.12 & 0.037 & 1.390 \\
\hline Build-out ratio (2009) & -1.931 & 0.211 & -9.16 & 0.000 & 1.380 & & & & & & & & & & \\
\hline Build-out ratio (1999) & & & & & & -1.081 & 0.161 & -6.70 & 0.000 & 1.590 & & & & & \\
\hline Build-out ratio (1989) & & & & & & & & & & & -0.427 & 0.253 & -1.69 & 0.095 & 3.480 \\
\hline \multicolumn{16}{|l|}{ Neighborhood Design: } \\
\hline Dead-ends & -0.013 & 0.005 & -2.47 & 0.015 & 2.780 & -0.011 & 0.006 & -1.85 & 0.067 & 3.140 & & & & & \\
\hline Dead-end Density & 1.377 & 0.487 & 2.83 & 0.005 & 1.320 & 1.269 & 0.496 & 2.56 & 0.012 & 1.280 & & & & & \\
\hline \multicolumn{16}{|l|}{ Distance to Amenities: } \\
\hline Elementary School $(\mathrm{ft})^{*}$ & -0.026 & 0.008 & -3.46 & 0.001 & 1.400 & & & & & & & & & & \\
\hline $\operatorname{Park}_{(\mathrm{ft})^{*}}$ & & & & & & -0.035 & 0.008 & -4.10 & 0.000 & 1.400 & & & & & \\
\hline \multicolumn{16}{|l|}{ Landscape Ecology: } \\
\hline Tree Ratio & & & & & & & & & & & -0.007 & 0.004 & -2.11 & 0.038 & 1.110 \\
\hline Mean Shape Index & & & & & & & & & & & 1.307 & 0.630 & 2.07 & 0.041 & 1.260 \\
\hline Patch Index & -0.045 & 0.022 & -2.11 & 0.037 & 1.470 & & & & & & & & & & \\
\hline \multicolumn{16}{|l|}{ Developed: } \\
\hline Year Built (ave) & 0.013 & 0.003 & 4.05 & 0.000 & 1.770 & 0.009 & 0.003 & 2.68 & 0.008 & 1.640 & 0.026 & 0.005 & 5.20 & 0.000 & 2.450 \\
\hline Constant $=$ & -22.10 & 1.889 & -3.85 & 0.000 & & -18.78 & 3.472 & -2.93 & 0.004 & & -43.42 & 9.853 & -3.30 & 0.001 & \\
\hline Adj R-squared = & & 0.524 & & & & & 0.546 & & & & & 0.485 & & & \\
\hline $\mathrm{N}=$ & & 149 & & & & & 112 & & & & & 87 & & & \\
\hline
\end{tabular}

* Coefficients and standard errors are multiplied by 1000. 
To gain insight into the causality of the relationship between development rate, build-out ratio and neighborhood turnover the temporal alignment can be reversed. Nine models were examined in this regard (c.f., Table 4). Inspired by Granger [30,31] a simple regression model of development rate and build-out ratio in the prior period, on the current neighborhood turnover was fit in each available period. The $\mathrm{R}^{2}$ of these models ranged from 0.283 to 0.481 depending on the period being examined; the individual coefficients are significant or marginally significant and in the predicted direction. Simple regressions were also fit for prior neighborhood turnover and build-out ratio on current development rate, and prior turnover and development rate on current build-out ratio in each available period. The $\mathrm{R}^{2}$ of these models ranged from 0.044 to 0.143 depending on the period being considered; the individual coefficients are less likely to be significant and the directions are varied. These results suggest that neighborhood turnover in the current period is the partial result of prior development rate and build-out ratio, but neither development rate or build-out ratio are significantly impacted by prior neighborhood turnover. Hence, the empirical evidence is inconsistent with prior turnover impacting development rate and build-out ratio; but the evidence that prior development rate and build-out impact neighborhood turnover rates is supported.

Table 4. Simple Regression Tests of Causality *.

\begin{tabular}{|c|c|c|c|}
\hline & $2010-2013$ & $2000-2009$ & 1990-1999 \\
\hline \multicolumn{4}{|l|}{ Transactions: } \\
\hline Development Process: Prior Period & 0.001 & 0.001 & 0.001 \\
\hline (prob.) & $(0.001)$ & $(0.146)$ & $(0.121)$ \\
\hline Buildout Ratio: Prior Period & -0.271 & -0.160 & -0.114 \\
\hline (prob.) & $(0.000)$ & $(0.000)$ & $(0.000)$ \\
\hline R-squared = & 0.481 & 0.385 & 0.283 \\
\hline \multicolumn{4}{|l|}{ Development Process: } \\
\hline Transactions: Prior Period & 49.492 & 16.200 & 10.268 \\
\hline (prob.) & $(0.007)$ & $(0.027)$ & $(0.112)$ \\
\hline Buildout Ratio: Prior Period & 50.294 & 4.028 & 4.433 \\
\hline (prob.) & $(0.004)$ & $(0.435)$ & $(0.106)$ \\
\hline R-squared = & 0.066 & 0.044 & 0.047 \\
\hline \multicolumn{4}{|l|}{ Buildout Ratio: } \\
\hline Transactions: Prior Period & & 0.043 & 0.027 \\
\hline (prob.) & & $(0.571)$ & $(0.883)$ \\
\hline Development Process: Prior Period & & 0.005 & 0.014 \\
\hline (prob.) & & $(0.002)$ & $(0.000)$ \\
\hline R-squared = & & 0.102 & 0.143 \\
\hline
\end{tabular}

\section{Implication and Discussion}

Rapid development has advantages for the developers, community, and even the individual residents. For the developers, timely development reduces the cost of holding the inventory of property and decreases their exposure to risk. For cities, finishing development projects in a timely manner means they come onto the tax roll at a higher level that includes the improvement to the properties. The residents are also served well by timely completion of the development because their neighborhood becomes more stable as it is completed. Some residents may even capitalize on the market by selling when the market value of their property increases as the risk of uncertainty decreases [6].

Yet, this paper identifies that as the rate of development increases, there is a tendency for neighborhood turnover to increase as well. Increased neighborhood turnover undermines the fundamental need for stability in neighborhoods. It can have positive effects on individual homeowners that reap the rewards of pioneer risk taking, but the negative effects on the character of the neighborhood can be long-lived, creating transitional neighborhoods with limited cohesion among residents. The analysis herein confirms that the more rapid the development, the more neighborhood 
turnover persists even in the context of other important factors, including: neighborhood design, street pattern, nearby amenities, landscape ecology, and the housing market. Neighborhood turnover has an unsettling effect on neighborhoods by disrupting social networks, creating the perception of instability, and changing existing circumstances. Urban planners, neighborhood designers, and developers often take extraordinary care to create neighborhood places that reduce stress, enhance well-being, and increase neighborhood satisfaction; however, this paper has shown that these efforts can be undermined by the increased neighborhood turnover associated with rapid development. When new residents move into an existing neighborhood, they may initially have to rely of their extant relationships, but as they become integrated into the community, they develop new relationships, attachments, and commitments to the people and the place that augment and replace those left behind. Developing these social networks in neighborhoods that are in constant transition with high turnover is likely to be difficult, as the neighborhood social networks are disrupted or even fail to develop. Neighborhoods that develop too quickly may create a neighborhood-in-transition character that perpetuates the continued change well into its lifetime. This suggests that virtual turnkey neighborhoods, where nearly all residents moved in at the same time, are likely to experience more difficulty establishing these connections that make a place a community, than neighborhoods that grow more organically. Simultaneously, as the current state of completion increases the number of sales transaction per year decreases, which suggests a stabilizing effect as the uncertainty of what the neighborhood will become in the future is replaced with historical experience.

Considering that subdivisions built as "spec-houses" are typically used as "starter-homes" for lower- and middle-income families, while larger "custom-homes" are built for a specific occupant and would thus provide an alternative explanation for the findings herein. Custom homes on large-lots would naturally develop more slowly and have subsequently reduced turnover rates, than smaller homes built on smaller lots for families in transition. While this argument seems to hold for individual residents, neighborhoods are an ecological unit comprised of multiple residents, parcels and surrounding circumstances. In any event, these variations are assessed in terms of the effects associated with number of parcels, appraised value, lot size, and diversity index by year built. But none of these control variables were significant $(\alpha<0.05)$ in either the full- or simplified-models (cf. Tables 2 and 3). Irrespective of these concerns the impact on the neighborhoods is both significant and enduring. Neighborhoods developed rapidly are more likely to experience higher turnover rates than those developed more deliberately.

Design decisions concerning street patterns, local amenity and landscape ecology all play important roles in creating and maintaining stable neighborhoods. The findings herein suggest that neighborhoods are physical places, comprised of lots of various sizes, street patterns, and nearby amenities. It also confirms that neighborhoods are ecological places with landscapes comprised of trees and grass. The relationship of these physical and ecological factors to neighborhood turnover suggests that neighborhood design elements play an important role in creating neighborhood satisfaction by creating the structure of the place. It is also clear that the process of development can have significant impact on neighborhood satisfaction. These results recognize that design matters, but they also recognize that implementation is important too. Both design and implementation have enduring perhaps even permanent effects on neighborhood satisfaction.

\section{Conclusions}

This paper examines the relationship between the development rate, build-out ratio and neighborhood turnover in terms of revealed preference data associated with residential properties. The findings herein indicate that the rate of development increases neighborhood turnover, while the proportion of neighborhood developed tends to stabilize turnover. Moreover, the findings indicate that these effects of development are sufficiently robust to persist in the context of other factors such as neighborhood design, nearby amenities and landscape ecology. These findings suggest that both design and implementation play important roles in creating neighborhood satisfaction. Design in 
terms of street pattern, distance to amenities such as schools, and landscape ecology in terms of proportion of trees and grass tend to increase stability by reducing neighborhood turnover. To the extent, a planners' goal is to create sustainable communities; these results suggest that the process of development cannot be ignored. The findings herein are consistent with King [16] who showed that the process of redevelopment in Chicago played a role in neighborhood satisfaction, the role of the process of development in creating neighborhood satisfaction has not been addressed previously. Development rates can be nearly instantaneous resulting in virtually turnkey neighborhoods, but they can also be processes that extend into multiple decades. The process of development is relatively short, while the resulting neighborhoods endure for generations. This means that there is a relatively short period of time when the process can be influenced that has effects that endure for extended periods. Most importantly, the planning mechanisms to influence the implementation process are limited relative to building codes and zoning laws used to regulate neighborhood design. The challenge for planners and community leaders is to identify mechanisms that can keep development in check without inhibiting timely progression.

This study has several limitations. First, it is a study of the processes of development in one city over a finite period. At worst, it represents little more than a quantitative case study of one southern university town. At best, it reflects on rapidly growing small to mid-sized cities throughout the country. Second, it is limited to revealed preference data that reflect on neighborhood satisfaction. This has the advantage of being the codified record of decisions about where to live, but it has the disadvantage of not being a direct measure of the underlying concept of interest. Third, the data are not a random sample of neighborhoods but rather a sample of the complete universe of neighborhoods in the study area. This means that, at best, the findings may be generalizable to similar populations under similar circumstances; at worst, these findings are simply descriptive of the case being studied. While one cannot know which of these extremes is valid, because of the rapid but not extreme growth rates in the city as well as the typical nature of auto-oriented communities and university towns, these results are expected to be relevant for many similar communities. The more similar the communities and conditions, the more generalizable the results are likely to be. Finally, the nature of the small to mid-size city means only a small number of neighborhoods can be examined, which allows for little comparison among various groups of neighborhoods (e.g., market class, design style, or period of development) for comparison. For example, because there were few subdivisions with significant water features (or golf courses) these could not be adequately studied herein.

Future research in this area should focus on some important issues that remain unclear. First, among these is the extent to which these findings can be generalized. Does the process of development impact neighborhood turnover in larger cities? Slower growing areas? Or even areas in decline? Second, because the rate of development increases neighborhood turnover in an ongoing manner and the fact that the current state of completion decreases turnover suggests that the effects of the development rate have some longevity but decline eventually. This poses interesting questions about how long the effects of rapid development last. Do they taper off slowly over time, or are there abrupt changes? At what point are they no longer relevant? Third, timely completion of development projects is driven by the developer's profit motive. This suggests a delicate balance between getting a development project completed in a timely manner and developing it too fast to create the stability the neighborhood needs. Some future work should look for the solutions that optimize the price (i.e., or value to the developer) while minimizing the negative impacts on neighborhood turnover (i.e., or maximizing stability in the neighborhood and community). Finally, it is important to develop and test various design, development, and planning mechanisms to regulate the development rates so that negative side effects can be minimized. Once this challenge is met and some tools are developed, then future research will need to test the efficacy of such tools individually and in various combinations.

Author Contributions: George O. Rogers contributed to the design of the study, analyses, interpretation of findings, and writing. Yunmi Park dedicated to collecting data, reviewing literature, and writing a manuscript.

Funding: This research received no external funding. 
Acknowledgments: This work was supported by the Ewha Womans University Research Grant of 2018.

Conflicts of Interest: Authors declare no conflict of interest. All authors have read and approved the final manuscript.

\section{Appendix A. Landscape Ecology Matrix}

Landscape shape index,

$$
\mathrm{LSI}=\left(0.25 \mathrm{E}^{\prime}\right) / \sqrt{A},
$$

where $E^{\prime}$ is total length of edge, including boundary, and $A$ is the area of the entire landscape area. LSI $\geq 1.0$ without limit, larger values indicate more complex shapes.

Mean shape index,

$$
\text { MSI }=\frac{\sum_{i=1}^{m} \sum_{j=1}^{n} \frac{0.25 p_{i j}}{\left(a_{i j}\right)^{1 / 2}}}{N P}
$$

where $p_{i j}$ is perimeter, $a_{i j}$ is area of patch $j$ in class $i, m$ is the number of patch types, $n$ is the number of patches and NP is the total number of parches in the landscape. MSI $\geq 1.0$ without limit as larger values indicate more complex shapes.

Patch cohesion index,

$$
\mathrm{PCI}=\left(1-\frac{\sum \mathrm{p}}{\sum \mathrm{p} \sqrt{\mathrm{a}}}\right)\left(1-\frac{1}{\sqrt{\mathrm{N}}}\right)^{-1} \times 100
$$

where $\mathrm{p}$ is patch perimeter, a is patch area, $\mathrm{N}$ is the number of cells on the map. $0 \leq \mathrm{PCI} \leq 100$ with larger values indicating more connectedness.

\section{References}

1. U.S. Census Bureau. New Residential Construction, Annual Rate for Housing Units Authorized in Permit-Issuing Places: United States, Seasonally Adjusted Single-Family Units. Available online: https: / / www.census.gov/construction/nrc/historical_data/index.html (accessed on 12 July 2017).

2. Jacobs, J. The Death and Life of Great American Cities; Vintage Books: New York, NY, USA, 1961.

3. Innes, J.E. Planning through consensus building: A new view of the comprehensive planning ideal. J. Am. Plan. Assoc. 1996, 62, 460-472. [CrossRef]

4. Miles, M.E.; Berens, G.; Weiss, M.A. Real Estate Development: Principles and Process; Urban Land Institute: Washington, DC, USA, 2000; p. 576.

5. Kohlhepp, D.B. The real estate development matrix. In Proceedings of the The American Real Estate Society Meetings, St. Petersburg, FL, USA, 10-14 April 2012.

6. Sirmans, C.F.; Turnbull, G.K.; Dombrow, J. Residential development, risk, and land prices. J. Reg. Sci. 1997, 37, 613-628. [CrossRef]

7. Talen, E.; Ellis, C. Beyond relativism reclaiming the search for good city form. J. Plan. Educ. Res. 2002, 22, 36-49. [CrossRef]

8. Madanipour, A. Ambiguities of urban design. Town Plan. Rev. 1997, 68, 363-383. [CrossRef]

9. Alexander, D.E.; Fairbridge, R.W. Encyclopedia of Environmental Science, 1st ed.; Springer: Houten, The Netherlands, 2006; Volume 20.

10. Bradford, S. Are TNDs selling? Builder 1993, 16, 76-79.

11. Hidalgo, M.C.; Hernandez, B. Place attachment: Conceptual and empirical questions. J. Environ. Psychol. 2001, 21, 273-281. [CrossRef]

12. Sorensen, J.; Gamez, J.; Currie, M. Windy ridge: A neighborhood built to fail. Appl. Geogr. 2014, 51, 8-25. [CrossRef]

13. Lucy, W.H.; American Planning Association. Foreclosing the Dream: How America's Housing Crisis Is Reshaping our Cities and Suburbs; American Planning Association Planners Press: Washington, DC, USA, 2010.

14. Lucy, W.H.; Phillips, D.L. Confronting Suburban Decline: Strategic Planning for Metropolitan Renewal; Island Press: Washington, DC, USA, 2000; p. 384. 
15. Lucy, W.H.; Phillips, D.L. Tomorrow's Cities, Tomorrow's Suburbs; American Planning Association Press: Washington, DC, USA, 2006; p. 337.

16. King, K. Jane Jacobs and 'The need for aged buildings': Neighbourhood historical development pace and community social relations. Urban Stud. 2013, 50, 2407-2424. [CrossRef] [PubMed]

17. Brown, B.B.; Perkins, D.D.; Brown, G. Incivilities, place attachment and crime: Block and individual effects. J. Environ. Psychol. 2004, 24, 359-371. [CrossRef]

18. Ross, C.E.; Reynolds, J.R.; Geis, K.J. The contingent meaning of neighborhood stability for residents' psychological well-being. Am. Sociol. Rev. 2000, 65, 581-597. [CrossRef]

19. Xie, M.; McDowall, D. The effects of residential turnover on household victimization. Criminology 2008, 46, 539-575. [CrossRef]

20. Woldoff, R.A. White Flight/Black Flight: The Dnamics of Rcial Change in an American Neighborhood; Cornell University Press: New York, NY, USA, 2011.

21. Schelling, T.C. Models of segregation. Am. Econ. Rev. 1969, 59, 488-493.

22. Schelling, T.C. Dynamic models of segregation. J. Math. Sociol. 1971, 1, 143-186. [CrossRef]

23. Frey, W.H. Central city white flight: Racial and nonracial causes. Am. Sociol. Rev. 1979, 44, 425-448. [CrossRef]

24. Goering, J.M. Neighborhood tipping and racial transition: A review of social science evidence. J. Am. Inst. Plan. 1978, 44, 68-78. [CrossRef]

25. Crowder, K. The racial context of white mobility: An individual-level assessment of the white flight hypothesis. Soc. Sci. Res. 2000, 29, 223-257. [CrossRef]

26. U.S. Census Bureau. Cumulative Estimates of Resident Population Change for Incorporated Places of 50,000 or More in 2010, Ranked by Percent Change: April 1, 2010 to July 1, 2013; U.S. Census Bureau: Suitland, MD, USA, 2014.

27. Samuelson, P.A. A note on the pure theory of consumer's behaviour. Economica 1938, 5, 61-71. [CrossRef]

28. Samuelson, P.A. Consumption theory in terms of revealed preference. Economica 1948, 15, 243-253. [CrossRef]

29. Simpson, E.H. Measurement of diversity. Nature 1949, 163, 688-688. [CrossRef]

30. Granger, C.W.J. Testing for causality: A personal viewpoint. J. Econ. Dyn. Control 1980, 2, 329-352. [CrossRef]

31. Granger, C.W.J. Some recent development in a concept of causality. J. Econ. 1988, 39, 199-211. [CrossRef]

(C) 2018 by the authors. Licensee MDPI, Basel, Switzerland. This article is an open access article distributed under the terms and conditions of the Creative Commons Attribution (CC BY) license (http:/ / creativecommons.org/licenses/by/4.0/). 